\title{
Estimation of the HEC-HMS model parameters in data-scarce regions. Application to the Ouergha watershed (Sebou, Morocco)
}

\author{
Hasna Moumni ${ }^{1 *}$, Karima Sebari ${ }^{1}$, Laila Stour $^{2}$, and Abdellatif Ahbari ${ }^{2}$ \\ ${ }^{1}$ Department of rural engineering, Hassan II Institute of Agronomy and Veterinary Medicine, Madinat Al Irfane. B.P. 6202-Instituts, \\ 10112-Rabat, Morocco \\ ${ }^{2}$ Laboratory of Process and Environment Engineering, Faculty of Sciences and Techniques of Mohammedia, Hassan II University of \\ Casablanca, B.P. 146, Mohammedia, Morocco
}

\begin{abstract}
The availability, accessibility and quality of data are significant obstacles to hydrological modelling. Estimating the initial values of the hydrological model" 's parameters is a laborious and determining task requiring much attention. Geographic information systems (GIS) and spatial remote sensing are prometting tools for processing and collecting data. In this work, we use an innovative approach to estimate the HEC-HMS hydrological model parameters from the soil map of Africa $(250 \mathrm{~m})$, the land use map GLC30, the depth to bedrock map, the digital elevation model and observed flow data. The estimation approach is applied to the Ouergha basin (Sebou, Morocco). The proposed approach's interest is to feed the HEC-HMS hydrological model with initial values of parameters close to the study area reality instead of using random parameters.
\end{abstract}

Keywords: HEC-HMS, parameter estimation, initial values, Ouergha basin

\footnotetext{
* Corresponding author: moumnihasna@gmail.com
} 


\section{Introduction}

Hydrological models are essential tools for water resources management studies. Hydrological models have widely been used for assessing flood risks[1], [2], simulating climate change impact on water resources[3], [4], quantifying land use-land cover impacts on hydrology[5], [6], and estimating erosion[7], [8]. However, several sources of uncertainties impact the results of hydrological modelling; the uncertainties on hydroclimatic data, the estimation of the model parameters and the uncertainties related to the model structure[9].

In developing countries, the major obstacle in hydrological modelling is the availability and accessibility of data[10]. The lack concerns hydroclimatic, soil and land use data. The hydroclimatic data are required to calibrate and update the model. The soil and land cover data are essential to simulate interception, transpiration and surface runoff processes. Estimating the input to the model becomes a difficult task due to the lack of data.

The goal of a good evaluation of the initial values of hydrological model parameters is to avoid convergence during the model calibration to mathematical solutions having no link with the physical characteristics of the basin. A good estimation will avoid converging to what [11] called "false positive" optimized parameters' values during model calibration and validation.

Ahbari et al. proposed a detailed methodology to calculate initial values of the HMS model formalisms mainly intended for African basins where quality, accessibility and availability of data is a real problem[11]. The approach proposed is based on free and accessible soil and land use data.

This work aims to establish a set of initial values following the proposed estimation approach in another different context of soil, topography and land cover. The approach is tested in the Ouergha basin, in Morocco. Ouergha basin is a vital basin that regulates the third of surface water resources and supplies the country's largest dam[12].

\section{Study area}

The Ouergha basin is located in the South-East of the Atlas in Morocco (Fig.1). It drains an area of $7200 \mathrm{~km} 2$ upstream of the M'jaara hydrometric station. The Ouergha is the main tributary of the Sebou. The basin elevation fluctuates between $75 \mathrm{~m}$ and $2435 \mathrm{~m}$. The climate of the basin is Mediterranean with an average rainfall of $740 \mathrm{~mm}$. The annual average temperature is $18{ }^{\circ} \mathrm{C}$. The Ouergha basin depends on surface water resources because of land's impermeability mainly composed of clay and marl and the limited groundwater resources[12], [13].

\section{Data required and maps elaborated}

\subsection{DEM data}

The DEM of the study area is downloaded from the platform earth explorer. The DEM resolution is $30 \mathrm{~m}$ ASTER GDEM V2.

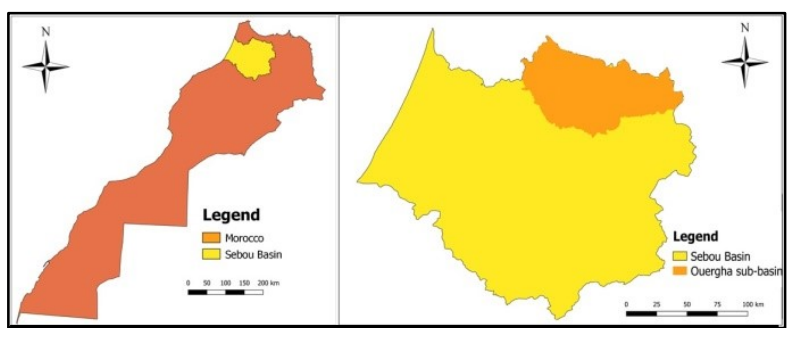

Fig.1. The situation of the Ouergha watershed (SebouMorocco)

\subsection{Discharge data}

The daily discharge at the basin outlet is required to calculate some initial values parameters. We use the daily discharge data recorded at the M'jaara hydrometric station located at the watershed outlet. The data are provided by the Sebou hydraulic basin agency.

\subsection{Soil data}

To avoid the soil data lack, Ahbari et al. suggest using data from the $250 \mathrm{~m}$ African Soil Grid project data[11]. The estimation approach variables are the percentages of clay, sand and silt in the soil. The data are downloadable from the ISRIC website.

\subsection{Land use data}

The ESA glob Cover data developed by The European Space Agency (ESA) (CCI, 2015) is used for land use data.

\subsection{Bedrock depth data}

For bedrock depth data, SoilGrids250m- Depth to bedrock map is used in this work. It is downloadable from the ISRIC website. In their study, [11]considered that the soil depth equals the six layers' total depth composing the soil in the African soil grid $250 \mathrm{~m}$ data because this map was not yet available. 


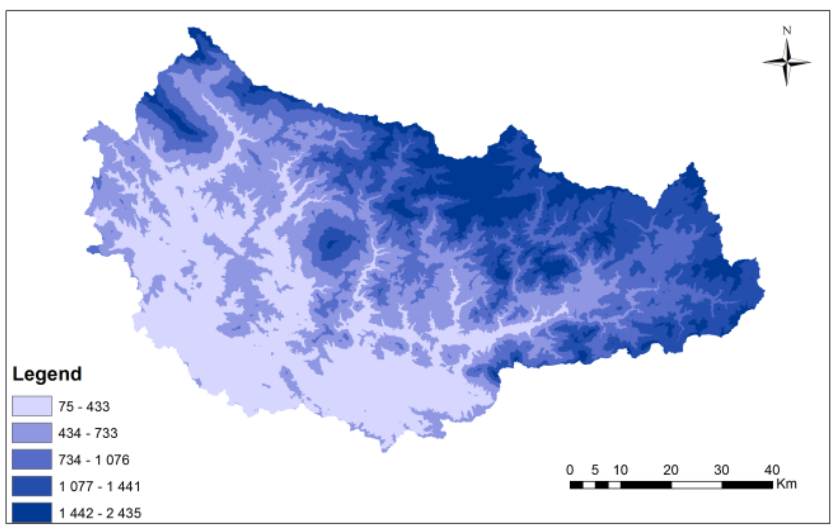

Fig. 2. Hypsometric map of the study area

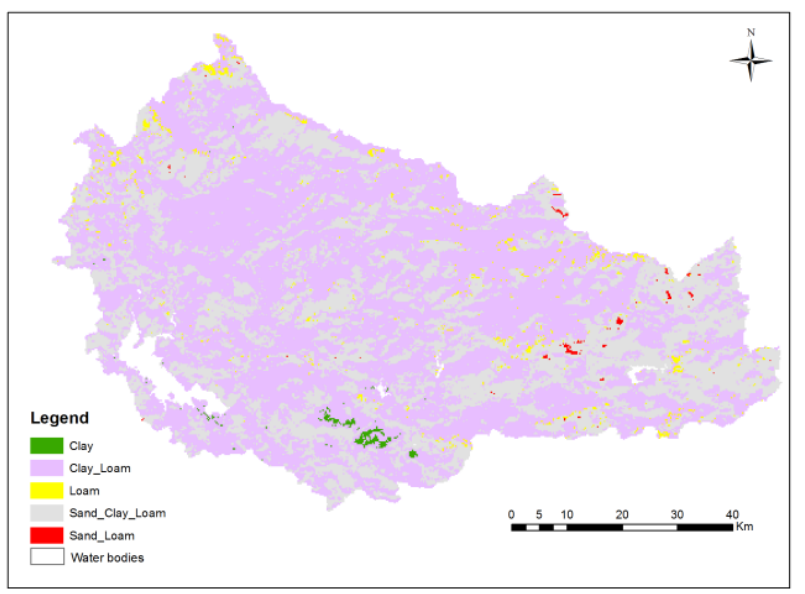

Fig.3. Soil map data of the study area

\section{Estimation approach}

Ahbari et al. presented an approach for parameters' initial values estimation adapted for African basins where quality, accessibility and availability of data are obstacles [11]. The approach is based on the use of available and accessible soil and land use data [11].

This work aims to evaluate the relevance of the data used as well as the calculation methodology in another different context. The estimation concerns the loss simulation models: the Soil Moisture Accounting (SMA) Model and the Deficit and constant loss method model, the simple surface method and the simple canopy method.

We are interested in these formalisms to evaluate the HEC-HMS model's parameters for a global and continuous hydrological modelling of water resources in the Ouergha basin.

The estimation method results and the values obtained for the case study are presented in tables 1,2 , 3. The detailed methodological guideline is presented by [11] for the calculation of initial values parameters for different formalisms of the HEC-HMS model.

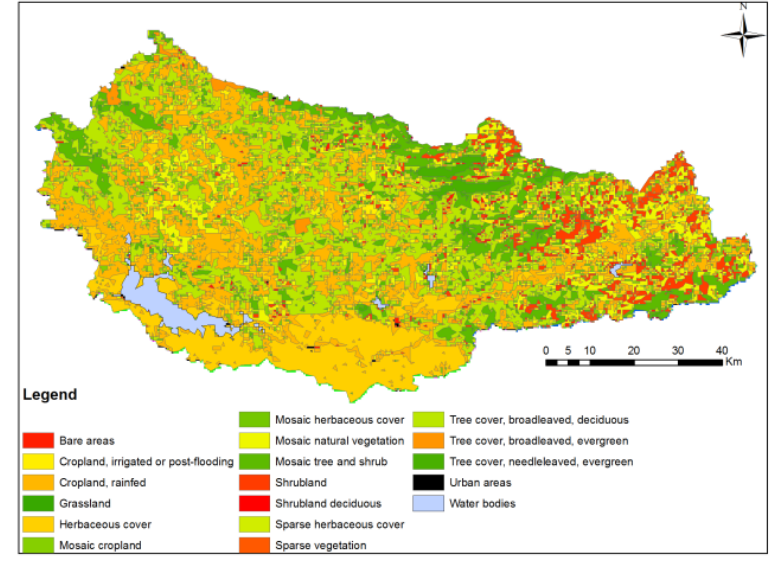

Fig.4. Land use data of the study area

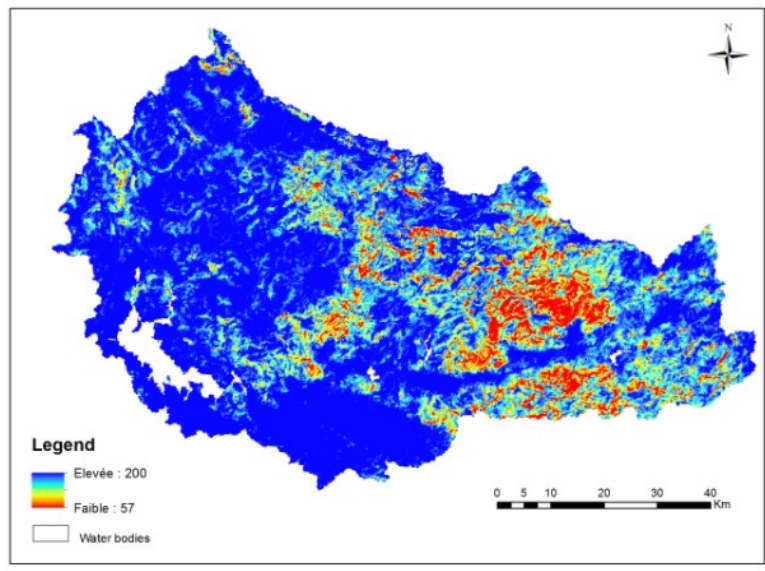

Fig.5. Bedrock depth map of the study area

Table 1: Initial values parameters estimation for Simple canopy method and Surface canopy method

\begin{tabular}{|c|c|}
\hline Parameters & Initial values of parameters \\
\hline Simple canopy method & $0 \%$ \\
\hline $\begin{array}{c}\text { Initial canopy storage } \\
(\%)\end{array}$ & $1,68 \mathrm{~mm}$ \\
\hline $\begin{array}{c}\text { Max canopy storage } \\
(\mathrm{mm})\end{array}$ & $0 \%$ \\
\hline $\begin{array}{c}\text { Surface canopy method } \\
\text { Initial surface storage } \\
(\%)\end{array}$ & $6,89 \mathrm{~mm}$ \\
\hline $\begin{array}{c}\text { Max surface storage } \\
(\mathrm{mm})\end{array}$ & \\
\hline
\end{tabular}

For the Initial canopy storage (\%), the guideline proposes to start the simulation following a dry period, which makes all the water stored in the basin depression either evaporated or infiltrated [11]. The basin's SCS land use map is used to estimate of the Max canopy storage ( $\mathrm{mm}$ ).

For the initial surface storage (\%), the guideline proposes to start the simulation following a dry period 
[11]. The maximum surface storage $(\mathrm{mm})$ is calculated according to the watershed slope (\%).

Table2: Initial values parameters estimation for deficit and constant loss method

\begin{tabular}{|c|c|}
\hline Parameters & Initial values of parameters \\
\hline $\begin{array}{c}\text { Percent of impervious } \\
(\%)\end{array}$ & $7,66 \%$ \\
\hline $\begin{array}{c}\text { Initial deficit } \\
(\mathrm{mm})\end{array}$ & $32.644 \mathrm{~mm}$ \\
\hline $\begin{array}{c}\text { Maximum deficit } \\
(\mathrm{mm})\end{array}$ & $81,82 \mathrm{~mm}$ \\
\hline $\begin{array}{c}\text { Constant rate } \\
(\mathrm{mm} / \mathrm{hr})\end{array}$ & $3.12 \mathrm{~mm} / \mathrm{hr}$ \\
\hline
\end{tabular}

For percent of impervious (\%), the guideline suggests relating it to the water plan percent as a minimum value [11]. Initial deficit $(\mathrm{mm})$ is calculated based on the field capacity related to the USDA texture class. Maximum deficit ( $\mathrm{mm})$ is obtained by calculating the product of the porosity and the soil depth. The constant rate $(\mathrm{mm} / \mathrm{hr})$ is estimated equal to the saturated hydraulic conductivity [11].

Table 3: Initial values parameters estimation for SMA loss method

\begin{tabular}{|c|c|}
\hline Parameters & $\begin{array}{c}\text { Initial values of } \\
\text { parameters }\end{array}$ \\
\hline $\begin{array}{l}\text { Percent of impervious } \\
(\%)\end{array}$ & $7,66 \%$ \\
\hline $\begin{array}{l}\text { The initial soil content, the } \\
\text { groundwater } 1 \text { initial content and the } \\
\text { groundwater } 2 \text { initial content }(\%)\end{array}$ & $0 \%$ \\
\hline $\begin{array}{c}\begin{array}{c}\text { Soil profile Storage } \\
(\mathrm{mm})\end{array} \\
\end{array}$ & $818.132 \mathrm{~mm}$ \\
\hline $\begin{array}{c}\text { Tension zone storage } \\
(\mathrm{mm})\end{array}$ & $630.878 \mathrm{~mm}$ \\
\hline $\begin{array}{l}\text { Max infiltration }(\mathrm{mm} / \mathrm{hr}) \text {, soil } \\
\text { percolation }(\mathrm{mm} / \mathrm{hr}) \text {, groundwater } 1 \\
\text { percolation }(\mathrm{mm} / \mathrm{hr}) \text {, groundwater } 2 \\
\text { percolation }(\mathrm{mm} / \mathrm{hr})\end{array}$ & $3,18 \mathrm{~mm} / \mathrm{hr}$ \\
\hline $\begin{array}{l}\text { Groundwater 1 storage (mm) } \\
\text { and coefficient (hr), }\end{array}$ & $\begin{array}{c}103.86 \mathrm{~mm}, 32.46 \mathrm{~h} \\
\text { respectively }\end{array}$ \\
\hline $\begin{array}{l}\text { groundwater } 2 \text { storage }(\mathrm{mm}) \\
\text { and coefficient }(\mathrm{hr})\end{array}$ & $\begin{array}{c}42960.48 \mathrm{~mm} \\
116.11 \mathrm{~h} \\
\text { respectively }\end{array}$ \\
\hline
\end{tabular}

For the percent of impervious (\%), the guideline indicates to consider as a minimum value the ratio of water plan. The initial soil content, the groundwater 1 initial content and the groundwater 2 initial content $(\%)$ were set to zero \% provided to start simulation following a dry period [11].

Soil profile storage $(\mathrm{mm})$ is estimated by calculating the product of soil layer's depth and porosity. Tension area storage $(\mathrm{mm})$ is estimated by calculating the product of soil layer's depth and field capacity.

Soil percolation $(\mathrm{mm} / \mathrm{hr})$, max infiltration $(\mathrm{mm} / \mathrm{hr})$, groundwater 1 percolation $(\mathrm{mm} / \mathrm{hr})$, groundwater 2 percolation $(\mathrm{mm} / \mathrm{hr})$ are estimated equal to the basin average hydraulic conductivity.

Groundwater storage $1(\mathrm{~mm})$ and coefficient $(\mathrm{h})$, groundwater storage $2(\mathrm{~mm})$ and coefficient $(\mathrm{h})$ are estimated based on the daily discharge through streamflow recession analysis [11].

\section{Discussion and Conclusion}

This work attends to use an innovative approach to determine the initial values of the HEC-HMS model parameters. The method is followed to carry out global and continuous modelling of the water resources in the Ouergha basin. The goal of a good evaluation of the initial values of the parameters is to avoid convergence during the calibration of the model to mathematical solutions having no link with the physical characteristics of the basin.

In addition to the product African Soil Grid $250 \mathrm{~m}$ and the GLC30 datasets, the novelty compared to the guide is the use of the SoilGrids250m- Depth to bedrock instead of considering that the soil depth is equal to the six layers' total depth composing the soil in the African soil grid $250 \mathrm{~m}$ data.

In a further article, the values of the parameters resulting from the above estimation approach will be used to start the hydrological simulation and will be followed by a calibration and validation process. The hydrological modelling results will be considered to assess the quality of the maps and data used for the estimation approach.

Acknowledgements : The authors are pleased to acknowledge the hydraulic basin agency of Sebou for providing data of the Ouergha basin.

\section{References}

[1] W. Li et al., ""Risk assessment and sensitivity analysis of flash floods in ungauged basins using coupled hydrologic and hydrodynamic models"," J. Hydrol., vol. 572, pp. 108-120, May 2019, doi: 10.1016/j.jhydrol.2019.03.002.

[2] D. B. Wijayarathne and P. Coulibaly, "'Identification of hydrological models for operational flood forecasting in St. John's, Newfoundland, Canada"," J. Hydrol. Reg. Stud., vol. 27, p. 100646, Feb. 2020, doi: 10.1016/j.ejrh.2019.100646.

[3] L. F. Dias et al., "'Integrating a hydrological model into regional water policies: Co-creation of climate change dynamic adaptive policy pathways for water resources in southern Portugal"," Environ. Sci. Policy, vol. 114, pp. 519-532, Dec. 2020, doi: 10.1016/j.envsci.2020.09.020.

[4] A. L. Kay, A. C. Rudd, M. Fry, G. Nash, and S. Allen, ""Climate change impacts on peak river flows: Combining national-scale hydrological modelling and probabilistic projections"," Clim. Risk Manag., vol. 31, p. 100263, Jan. 2021, doi: 10.1016/j.crm.2020.100263. 
[5] A. Birhanu, I. Masih, P. van der Zaag, J. Nyssen, and X. Cai, "'Impacts of land use and land cover changes on hydrology of the Gumara catchment, Ethiopia"," Phys. Chem. Earth Parts ABC, vol. 112, pp. 165-174, Aug. 2019, doi: 10.1016/j.pce.2019.01.006.

[6] S. M. Z. Younis and A. Ammar, "'Quantification of impact of changes in land use-land cover on hydrology in the upper Indus Basin, Pakistan"," Egypt. J. Remote Sens. Space Sci., Nov. 2017, doi: 10.1016/j.ejrs.2017.11.001.

[7] A. Millares, Z. Gulliver, and M. J. Polo, ""Scale effects on the estimation of erosion thresholds through a distributed and physically-based hydrological model"," Geomorphology, vol. 153154, pp. 115-126, Jun. 2012, doi: 10.1016/j.geomorph.2012.02.016.

[8] T. Zi, M. Kumar, G. Kiely, C. Lewis, and J. Albertson, "'Simulating the spatio-temporal dynamics of soil erosion, deposition, and yield using a coupled sediment dynamics and 3D distributed hydrologic model"," Environ. Model. Softw., vol. 83, pp. 310-325, Sep. 2016, doi: 10.1016/j.envsoft.2016.06.004.

[9] H. Wang, E. D. Brill, R. S. Ranjithan, and A. Sankarasubramanian, ""A framework for incorporating ecological releases in single reservoir operation"," Adv. Water Resour., vol. 78, pp. 9-21, Apr. 2015, doi: 10.1016/j.advwatres.2015.01.006.

[10] Y. T. Dile et al., ""Advances in water resources research in the Upper Blue Nile basin and the way forward: A review"," J. Hydrol., vol. 560, pp. 407-423, May 2018, doi: 10.1016/j.jhydrol.2018.03.042.

[11] A. Ahbari, L. Stour, A. Agoumi, and N. Serhir, ""Estimation of initial values of the HMS model parameters: Application to the basin of Bin El Ouidane (Azilal, Morocco")," J Mater Env. Sci, vol. 9, pp. 305-317, 2018.

[12] S. Senoussi et al., "Changements climatiques et ressources en eau Bassin versant de I'Ouergha (Maroc)," Hydroécologie Appliquée, vol. 11, pp. 163-182, 1999, doi: 10.1051/hydro:1999007.

[13] S. Boukrim, N. Sadkaoui, A. Lahrach, and A. Chaouni, "ETUDE D'IMPACT DES CHANGEMENTS CLIMATIQUES SUR LES RESSOURCES HYDRIQUES DU BASSIN VERSANT DE L'OUERGHA (RIF - MAROC) IMPACT OF CLIMATE CHANGE ON WATER RESOURCES OF THE OUERGHA WATERSHED (RIF, MOROCCO)," J. Eau Environ., vol. 10, no. 19, pp. 42-55, Dec. 2011. 